BMJ Open

Diabetes

Research

\& Care

\section{Plasma 1-deoxysphingolipids are predictive biomarkers for type 2 diabetes mellitus}

To cite: 0 thman $A$, Saely $\mathrm{CH}$, Muendlein A, et al. Plasma 1-deoxysphingolipids are predictive biomarkers for type 2 diabetes mellitus. BMJ Open Diabetes Research and Care 2015;3:e000073. doi:10.1136/bmjdrc-2014000073

Received 27 November 2014 Revised 29 January 2015 Accepted 24 February 2015

\section{(1) CrossMark}

${ }^{1}$ Institute for Clinical Chemistry, University Hospital Zurich, Zurich, Switzerland

${ }^{2}$ Centre for Integrative Human Physiology, University of Zurich, Zurich, Switzerland ${ }^{3}$ Institute of Experimental and Clinical Pharmacology and Toxicology, University of Lübeck, Lübeck, Germany ${ }^{4}$ Vorarlberg Institute for Vascular Investigation and Treatment (VIVIT), Feldkirch, Austria

${ }^{5}$ Department of Medicine and Cardiology, Academic Teaching Hospital Feldkirch, Feldkirch, Austria

${ }^{6}$ Private University of the Principality of Liechtenstein, Triesen, Liechtenstein ${ }^{7}$ Drexel University College of Medicine, Philadelphia, Pennsylvania, USA

Correspondence to Dr Thorsten Hornemann; thorsten.hornemann@usz.ch

\author{
Alaa Othman, ${ }^{1,2,3}$ Christoph H Saely, ${ }^{4,5,6}$ Axel Muendlein, ${ }^{4,5,6}$ \\ Alexander Vonbank, ${ }^{4,5,6}$ Heinz Drexel, ${ }^{4,5,6,7}$ Arnold von Eckardstein,, ${ }^{1,2}$ \\ Thorsten Hornemann ${ }^{1,2}$
}

\section{ABSTRACT}

Objective: Serine palmitoyltransferase (SPT) catalyzes the condensation of serine and palmitoyl coenzyme A, the first step in the de novo sphingolipid synthesis. Apart from these canonical substrates, SPT can also metabolize alanine and other acyl coenzyme As. This forms a spectrum of atypical sphingoid bases which are altered in the context of the metabolic syndrome (MetS) and type 2 diabetes mellitus (T2DM). We investigated whether atypical sphingolipids can be used as prospective markers to predict the incidence of T2DM.

Research design and methods: Using liquid chromatography/mass spectrometry, we analyzed the sphingoid base profile in a prospective cohort with 339 individuals. All individuals were followed up for a period of 8 years.

Results: Confirming earlier results, we found 1-deoxysphingolipids (1-deoxySLs) to be significantly elevated in patients with MetS, impaired fasting glucose, and T2DM. Patients who developed T2DM during the follow-up period $(\mathrm{n}=32)$ showed significantly higher 1-deoxySL levels at baseline compared with those who did not develop T2DM until the end of the study ( $n=70)$. 1-Deoxysphingosine levels were independent predictors for T2DM even after adjusting for glycated hemoglobin (standardized adjusted OR=2.1, $\mathrm{Cl} 95 \%$ (1.19 to 3.71); $p=0.010$ ), MetS (standardized adjusted OR=1.97, $\mathrm{Cl} 95 \%$ (1.13 to 3.43 ); $p=0.017$ ), and other risk factors such as age, sex, BMI, and lipid-lowering drugs. Similar results were observed for the 1-deoxysphinganine levels.

Conclusions: Our results support a novel role for 1-deoxySL as predictive biomarkers for the development of T2DM in risk patients and warrants further larger prospective trials in lower risk cohorts.

\section{INTRODUCTION}

Diabetes mellitus type 2 (T2DM) remains a major cause of mortality and morbidity worldwide, despite the advances in risk prediction, diagnosis, and management. Traditional risk factors such as impaired fasting glucose (IFG) and impaired glucose tolerance fail to predict almost $50 \%$ of the

\section{Key messages}

1-Deoxysphingolipids (1-deoxySLs) are significantly elevated in patients with impaired fasting glucose, metabolic syndrome (MetS), and T2DM.

- 1-DeoxySLS are independent predictors for the risk to develop T2DM even after adjusting for glycated hemoglobin and the presence of MetS.

Although plasma triglycerides and 1-deoxySLs showed a high collinearity, stepwise logistic regression analysis revealed 1-deoxySLs as independent predictors for T2DM.

patients who will develop T2DM. ${ }^{1}{ }^{2}$ This fact has fueled an expanding research pursuit to identify risk factors and novel biomarkers to improve risk prediction. ${ }^{3}{ }^{4}$ With the progress in mass spectrometry and nuclear magnetic resonance spectroscopy, many blind spots in the human plasma metabolome and lipidome are becoming visible and quantifiable. In fact, several metabolites such as acylcarnitines, amino acids, phospholipids, and also sphingolipids have become candidates of biomarkers for the prediction of future T2DM. $^{5-7}$

Sphingolipids comprise a heterogeneous class of lipids including free sphingoid bases, ceramides, sphingomyelins, and glycosphingolipids. Sphingoid bases are the shared structural element in all sphingolipids and typically formed by the condensation of L-serine and palmitoyl coenzyme A. This reaction is catalyzed by the enzyme serine palmitoyltransferase $(\mathrm{SPT})^{8-10}$ forming C18-sphinganine $\left(\mathrm{C}_{18} \mathrm{SA}\right)$, which is then subsequently $\mathrm{N}$-acylated to (dihydro)-ceramides. Ceramides are bioactive lipids which serve as building blocks for the synthesis of complex sphingolipids like sphingomyelins or gylcosphingolipids.

There is increasing evidence that sphingolipids are actively involved in the development of T2DM. ${ }^{11}$ Ceramides were shown to 
counteract the insulin action on glucose uptake and glycogen synthesis by inhibiting protein kinase B/Akt through different mechanisms, ${ }^{12}$ and it was demonstrated recently that many of the beneficial effects of adiponectin on $\beta$-cell survival in T2DM are linked to its lowering effect on intracellular ceramide levels. ${ }^{13}$ Moreover, plasma levels of ceramides were found to be elevated in patients with T2DM ${ }^{14}$ and to correlate with the degree of insulin resistance in these patients. In contrast, sphingomyelin and gylcosphingolipids were found to be decreased in plasma of diabetic monkeys. ${ }^{15}$ Myriocin, a potent SPT inhibitor, was shown to improve insulin resistance and preclude the development of T2DM in animal models. ${ }^{16}$ Apart from the canonical substrates, SPT is also able to metabolize other acyl coenzyme As in the range of $\mathrm{C}_{12}$ to $\mathrm{C}_{18}$, which results in a spectrum of sphingoid bases with variable carbon chain length. Under certain conditions, SPT can also use other amino acids such as L-alanine and partly also glycine as alternative substrates. ${ }^{17}$ This generates an atypical class of neurotoxic 1-deoxysphingolipids (1-deoxySL) which lack the $\mathrm{C}_{1}$ hydroxyl group of canonical sphingolipids. SPT is positioned at a metabolic cross-point which metabolically interconnects fatty acid, amino acid (serine, alanine, and glycine), and thereby indirectly also the carbohydrate metabolism.

We showed previously that 1-deoxyspingolipids (1-deoxySLs) are significantly elevated in the plasma of individuals with metabolic syndrome $(\mathrm{MetS})^{18}$ and T2DM. ${ }^{19}$ In this follow-up study, we aimed to investigate the ability of 1-deoxySLs to predict incident diabetes by analyzing the sphingoid base profile in a prospective cohort with 339 individuals.

\section{RESEARCH DESIGN AND METHODS \\ Patients and study design}

For this study, a group of 339 patients were selected from a prospective cohort study of patients who underwent coronary angiography for the evaluation of established or suspected stable coronary artery disease (CAD).$^{20}$ The group was selected based on the availability of baseline and follow-up data for T2DM. The study participants were enrolled into the study between September 1999 and October 2000. Anthropometric data were collected, clinical chemistry laboratory parameters were measured, and coronary angiography (Judkin's technique) was performed on all study participants at baseline. Coronary artery stenoses with lumen narrowing of $50 \%$ or more were considered significant, and coronary arteries were defined as normal in the absence of any visible lumen narrowing at angiography. All participants gave written informed consent.

\section{Diagnosis}

Diabetes at baseline was diagnosed according to the WHO criteria, that is, fasting glucose levels $\geq 7 \mathrm{mmol} / \mathrm{L}$ $(126 \mathrm{mg} / \mathrm{dL})$, plasma glucose levels $\geq 11.1 \mathrm{mmol} / \mathrm{L}$
(200 mg/dL) $2 \mathrm{~h}$ after an oral glucose challenge (75 g), or a previous physician diagnosis of T2DM.

Metabolic syndrome at baseline was defined according to the criteria of the National Cholesterol Education Program-Adult Treatment Panel III criteria, if three or more of the following criteria were met: waist circumference $>102 \mathrm{~cm}$ in men or $>88 \mathrm{~cm}$ in women; triglycerides (TGs) $\geq 1.7 \mathrm{mmol} / \mathrm{L}(150 \mathrm{mg} / \mathrm{dL})$; high-density lipoprotein (HDL) cholesterol $<1.0 \mathrm{mmol} / \mathrm{L} \quad(40 \mathrm{mg} / \mathrm{dL})$ in men or $<1.3 \mathrm{mmol} / \mathrm{L}(50 \mathrm{mg} / \mathrm{dL})$ in women; blood pressure $\geq 130 / \geq 85 \mathrm{~mm} \mathrm{Hg} ;$ and fasting glucose $\geq 6.1 \mathrm{mmol} / \mathrm{L} \quad(110 \mathrm{mg} / \mathrm{dL})$. Patients with fasting glucose $\geq 7 \mathrm{mmol} / \mathrm{L}(126 \mathrm{mg} / \mathrm{dL})$ at baseline were diagnosed with T2DM, patients with fasting glucose between 5.6 and $6.9 \mathrm{mmol} / \mathrm{L}(100-125 \mathrm{mg} / \mathrm{dL})$ were diagnosed as IFG while those with fasting glucose $<5.6 \mathrm{mmol} / \mathrm{L}$ were diagnosed as normal fasting glucose (NFG).

\section{Prospective study}

For the diagnosis of incident T2DM, blood samples were collected 2, 4, 6 and 8 years after enrollment. Individuals were considered to have incident diabetes if one of the three criteria was met at any of the follow-up examinations: fasting glucose levels $\geq 7 \mathrm{mmol} / \mathrm{L}(126 \mathrm{mg} / \mathrm{dL})$, plasma glucose levels $\geq 11.1 \mathrm{mmol} / \mathrm{L}(200 \mathrm{mg} / \mathrm{dL}) 2 \mathrm{~h}$ after an oral glucose challenge $(75 \mathrm{~g})$, or the clinical diagnosis of T2DM by a physician during the follow-up period. Individuals were classified to be free from incident T2DM if both conditions were met; fasting glucose levels $<7 \mathrm{mmol} / \mathrm{L} \quad(126 \mathrm{mg} / \mathrm{dL})$ and plasma glucose levels $<11.1 \mathrm{mmol} / \mathrm{L}$ (200 mg/dL) $2 \mathrm{~h}$ after an oral challenge with $75 \mathrm{~g}$ glucose at all follow-up visits. Individuals with missing values for fasting plasma glucose or $2 \mathrm{~h}$ post-glucose challenge were excluded. From the total cohort, 105 participants fulfilled either the criteria of incident T2DM $(n=32)$ or the absence of incident T2DM $(n=70)$ and were included in the prospective analysis.

\section{Clinical chemistry}

Venous blood samples were collected after overnight fasting and at least $12 \mathrm{~h}$ before angiography. Laboratory analysis was performed on fresh serum or blood samples. Glycated hemoglobin (HbAlc) was analyzed by high-performance liquid chromatography on a Menarini-Arkray KDK HA 8140 (Arkray KDK, Kyoto, Japan). Triacylglycerols, total cholesterol, HDL, and other clinical chemistry variables were measured on a Hitachi 717 or 911 system (Roche).

\section{Sphingolipid analysis}

The sphingoid base profile was analyzed as described before $^{18}$ with some modifications. Briefly, $0.5 \mathrm{~mL}$ methanol including $200 \mathrm{pmol}$ of the internal standards d7-sphingosine and d7-sphinganine (d7SA, d7SO; Avanti Polar Lipids, Alabaster, Alabama, USA) was added to $100 \mu \mathrm{L}$ of plasma and extracted for $1 \mathrm{~h}$ under agitation on a thermomixer at $37^{\circ} \mathrm{C}$. Precipitated proteins were 
pelleted by centrifugation and the supernatant transferred to a new tube. For lipid hydrolysis, $75 \mu \mathrm{L}$ of methanolic $\mathrm{HCl}\left(1 \mathrm{~N} \mathrm{HCl}\right.$ and $10 \mathrm{M} \mathrm{H}_{2} \mathrm{O}$ in methanol) was added to the supernatant and incubated for $16 \mathrm{~h}$ at $65^{\circ} \mathrm{C}$. This was followed by the addition of $100 \mu \mathrm{L}$ of $10 \mathrm{M} \mathrm{KOH}$ to neutralize the $\mathrm{HCl}$ and hydrolyze the phospholipids. To this mix, $625 \mu \mathrm{L}$ chloroform was added. Then, $100 \mu \mathrm{L} 2 \mathrm{~N}$ ammonium hydroxide and $0.5 \mathrm{~mL}$ alkaline water were added to complete the phase separation. The mix was then vortexed and centrifuged at $16000 \mathrm{~g}$ for $5 \mathrm{~min}$. After centrifugation, the upper phase was discarded and the lower organic phase was washed 2-3 times with alkaline water ( $\mathrm{pH} 10.3)$. Finally, the organic phase was dried under $\mathrm{N}_{2}$ and kept at $-20^{\circ}$ $\mathrm{C}$ until analysis.

The sphingoid bases were separated on a $\mathrm{C}_{18}$ column (Uptispere $120 \AA ̊, 5 \mu \mathrm{m}, 125 \times 2 \mathrm{~mm}$, Interchim, Montluçon, France) and analyzed on a TSQ Quantum Ultra mass spectrometer (Thermo, Reinach, BL, Switzerland). Each sample was measured as a singleton. Intra assay and inter assay coefficient of variation $(\%)$ of the method was between $5 \%$ and $20 \%$.

Table 1 Baseline characteristics of patients with MetS and individuals free of MetS

\begin{tabular}{|c|c|c|c|}
\hline & No MetS at baseline $(n=192)$ & MetS at baseline $(n=147)$ & p Value \\
\hline Age (years) & $64.2 \pm 10.1$ & $61.2 \pm 9.7$ & 0.006 \\
\hline Sex (female) & $65(33.85 \%)$ & $43(29.25 \%)$ & 0.367 \\
\hline Hypertension (WHO) & 78 (40.63\%) & $98(66.67 \%)$ & 1.98E-06 \\
\hline T2DM (baseline) & $31(16.15 \%)$ & $77(52.38 \%)$ & $1.28 \mathrm{E}-12$ \\
\hline History of smoking & $106(55.21 \%)$ & $97(65.99 \%)$ & 0.045 \\
\hline Coronary artery stenosis $>50 \%$ & $112(58.33 \%)$ & $98(66.67 \%)$ & 0.117 \\
\hline BMI & $26 \pm 4.1$ & $28.9 \pm 4.2$ & 4.59E-11 \\
\hline Waist circumference $(\mathrm{cm})$ & $91.6 \pm 10.7$ & $101.6 \pm 11.4$ & 3.92E-14 \\
\hline Waist-to-hip ratio & $0.9 \pm 0.1$ & $1.0 \pm 0.1$ & 2.91E-08 \\
\hline Cholesterol (mmol/L) & $5.6 \pm 1$ & $5.6 \pm 1.2$ & 0.478 \\
\hline LDL (mmol/L) & $3.4 \pm 0.8$ & $3.3 \pm 0.9$ & 0.068 \\
\hline HDL (mmol/L) & $1.4 \pm 0.4$ & $1 \pm 0.3$ & 4.49E-19 \\
\hline Triglycerides (mmol/L) & $1.4 \pm 0.5$ & $2.5 \pm 1.6$ & 3.18E-22 \\
\hline Glucose (mmol/L) & $6 \pm 1.8$ & $7.7 \pm 2.5$ & 9.56E-20 \\
\hline HbA1c (\%) & $6 \pm 0.8$ & $6.7 \pm 1.4$ & 2.06E-07 \\
\hline Insulin ( $\mu \mathrm{U} / \mathrm{mL})$ & $9.1 \pm 7.6$ & $16.7 \pm 15.5$ & 2.98E-13 \\
\hline HOMA-IR & $2.4 \pm 2.2$ & $5.5 \pm 4.5$ & 2.0E-18 \\
\hline Systolic BP & $130.8 \pm 21.1$ & $145 \pm 21$ & 4.82E-10 \\
\hline Diastolic BP & $76.3 \pm 12.3$ & $82.2 \pm 12.2$ & 8.29E-06 \\
\hline CRP & $0.7 \pm 1$ & $1.1 \pm 1.7$ & 2.65E-05 \\
\hline Serum potassium & $4.4 \pm 0.4$ & $4.4 \pm 0.5$ & 0.656 \\
\hline Creatinine (mg/dL) & $1.1 \pm 0.5$ & $1.2 \pm 0.7$ & 0.053 \\
\hline GFR (Mayo) & $86.6 \pm 18.6$ & $85 \pm 21.4$ & 0.973 \\
\hline T2DM treatment & $31(16.15 \%)$ & $77(52.38 \%)$ & 1.28E-12 \\
\hline Diuretics & $58(30.21 \%)$ & $60(40.82 \%)$ & 0.042 \\
\hline Antihypertensive drugs & $149(77.6 \%)$ & $127(86.39 \%)$ & 0.039 \\
\hline Lipid-lowering drugs & $90(46.88 \%)$ & 79 (53.74\%) & 0.210 \\
\hline \multicolumn{4}{|l|}{ Plasma sphingolipids } \\
\hline C16SO ( $\mu \mathrm{mol} / \mathrm{L})$ & $15.32 \pm 5.38$ & $14.19 \pm 5.4$ & 0.022 \\
\hline C16SA ( $\mu \mathrm{mol} / \mathrm{L})$ & $0.45 \pm 0.19$ & $0.5 \pm 0.29$ & 0.220 \\
\hline C17SO ( $\mu \mathrm{mol} / \mathrm{L})$ & $8.13 \pm 2.73$ & $7.22 \pm 2.45$ & 0.002 \\
\hline C18PhytoSO ( $\mu \mathrm{mol} / \mathrm{L})$ & $0.12 \pm 0.04$ & $0.11 \pm 0.05$ & 0.066 \\
\hline C18SAdiene ( $\mu \mathrm{mol} / \mathrm{L})$ & $28.22 \pm 7.71$ & $26.22 \pm 7.88$ & 0.014 \\
\hline C18SO ( $\mu \mathrm{mol} / \mathrm{L})$ & $94.77 \pm 18.48$ & $89.79 \pm 22.77$ & 0.019 \\
\hline C18SA ( $\mu \mathrm{mol} / \mathrm{L})$ & $3.21 \pm 1.04$ & $3.66 \pm 1.84$ & 0.065 \\
\hline C19SO ( $\mu \mathrm{mol} / \mathrm{L})$ & $2.88 \pm 1.2$ & $2.65 \pm 1.19$ & 0.043 \\
\hline C20SO ( $\mu \mathrm{mol} / \mathrm{L})$ & $0.17 \pm 0.05$ & $0.18 \pm 0.06$ & 0.039 \\
\hline C20SA ( $\mu \mathrm{mol} / \mathrm{L})$ & $0.02 \pm 0.01$ & $0.03 \pm 0.01$ & 2.81E-04 \\
\hline 1-deoxySO ( $\mu \mathrm{mol} / \mathrm{L})$ & $0.15 \pm 0.09$ & $0.21 \pm 0.14$ & 5.65E-06 \\
\hline 1-deoxySA ( $\mu \mathrm{mol} / \mathrm{L})$ & $0.07 \pm 0.03$ & $0.09 \pm 0.06$ & 3.26E-05 \\
\hline
\end{tabular}

Values are shown as mean \pm SD for the continuous variables and numbers and per cent of total for the categorical variables. $p$ Values were calculated using the unpaired two-sided $t$ test on the log-transformed continuous variables. For the categorical variables, the $p$ value was calculated using the $\chi^{2}$ test. Variables in bold font have significant differences after the Bonferroni correction $(p<0.001)$

$\mathrm{BMI}$, body mass index; CRP, C reaction protein; GFR (Mayo), Glomerular filtration rate (Mayo equation); Hb, hemoglobin; HbA1c, glycated $\mathrm{Hb}$; HDL, high-density lipoprotein; HOMA-IR, homeostatic model assessment-insulin resistance; LDL, low-density lipoprotein; MetS, metabolic syndrome; SA, sphinganine; SO, sphingosine; T2DM, type 2 diabetes mellitus. 
Sphingoid bases in plasma are typically $\mathrm{N}$-acylated and conjugated to different headgroups. ${ }^{21}$ It is important to note that 1-deoxySLs lack the $\mathrm{C}_{1}$ hydroxyl group of typical SLs and therefore cannot form complex sphingolipids such as sphingomyelin or glycosphingolipids. Plasma 1-deoxySLs can be present as 1-deoxysphinganine (1-deoxySA) or 1-deoxysphingosine (1-deoxySO)) and in the N-acylated forms (1-deoxy-dihydro-ceramides and 1deoxyceramides, respectively). ${ }^{22}$ We performed an acid/base hydrolysis prior to analysis and quantified the total amount of all long-chain bases (which reflects the SPT activity). At that stage, we cannot distinguish between the free base and $N$-acyls anymore. Therefore, the reported sphingoid base concentrations do not reflect the original levels of free

Table 2 Baseline characteristics of patients with NFG, IFG, and T2DM

\begin{tabular}{|c|c|c|c|c|}
\hline & $\begin{array}{l}\text { NFG at baseline } \\
(n=124)\end{array}$ & $\begin{array}{l}\text { IFG at baseline } \\
(n=107)\end{array}$ & $\begin{array}{l}\text { T2DM at baseline } \\
(n=108)\end{array}$ & p Value \\
\hline Age (years) & $62.5 \pm 10.3$ & $63.6 \pm 10.1$ & $62.7 \pm 9.7$ & 0.708 \\
\hline Sex (female) & $48(38.71 \%)$ & $27(25.23 \%)$ & $33(30.56 \%)$ & 0.085 \\
\hline Hypertension (WHO) & $56(45.16 \%)$ & $64(59.81 \%)$ & $56(51.85 \%)$ & 0.085 \\
\hline History of smoking & $70(56.45 \%)$ & $61(57.01 \%)$ & $72(66.67 \%)$ & 0.218 \\
\hline Coronary artery stenosis $>50 \%$ & $71(57.26 \%)$ & $65(60.75 \%)$ & $74(68.52 \%)$ & 0.202 \\
\hline MetS ATP III Definition & $26(20.97 \%)$ & $44(41.12 \%)^{\star}$ & $77(71.3 \%)^{\star} \S$ & 1.01E-13 \\
\hline $\mathrm{BMI}$ & $26.4 \pm 4.6$ & $27.3 \pm 4$ & $28.2 \pm 4.3$ & 0.006 \\
\hline Waist circumference $(\mathrm{cm})$ & $91.9 \pm 12$ & $97 \pm 10.7$ & $99.4 \pm 12.2^{*}$ & 9.54E-06 \\
\hline Waist-to-hip ratio & $0.9 \pm 0.1$ & $1 \pm 0.1$ & $1 \pm 0.1^{*}$ & 1.60E-04 \\
\hline Cholesterol (mmol/L) & $5.6 \pm 1.1$ & $5.7 \pm 1$ & $5.4 \pm 1.2$ & 0.133 \\
\hline $\mathrm{LDL}(\mathrm{mmol} / \mathrm{L})$ & $3.4 \pm 0.8$ & $3.5 \pm 0.8$ & $3.1 \pm 0.9$ & 0.001 \\
\hline $\mathrm{HDL}(\mathrm{mmol} / \mathrm{L})$ & $1.3 \pm 0.4$ & $1.3 \pm 0.4$ & $1.1 \pm 0.4$ & 0.001 \\
\hline Triglycerides (mmol/L) & $1.7 \pm 1.1$ & $1.7 \pm 0.8$ & $2.3 \pm 1.7^{\star}$ & 3.39E-05 \\
\hline Glucose (mmol/L) & $5.3 \pm 0.9$ & $6.2 \pm 0.5^{\star}$ & $8.9 \pm 2.8^{*} \S$ & 7.81E-55 \\
\hline HbA1c (\%) & $5.8 \pm 0.5$ & $5.9 \pm 0.5$ & $7.5 \pm 1.4^{*}$ & 4.44E-44 \\
\hline Insulin ( $\mu \mathrm{U} / \mathrm{mL})$ & $9.4 \pm 13.5$ & $12.9 \pm 10.5^{\star}$ & $15.4 \pm 11.8 \star \S$ & 2.39E-08 \\
\hline HOMA-IR & $1.9 \pm 1.2$ & $3.6 \pm 3.1^{*}$ & $5.9 \pm 4.9 * \S$ & 3.64E-23 \\
\hline Systolic BP & $133.3 \pm 22.7$ & $138.7 \pm 21.3$ & $139.6 \pm 22$ & 0.040 \\
\hline Diastolic BP & $77.9 \pm 12.6$ & $79.7 \pm 11.2$ & $79.2 \pm 13.9$ & 0.457 \\
\hline CRP & $0.7 \pm 1.1$ & $0.9 \pm 1.7$ & $1 \pm 1.2$ & 0.058 \\
\hline Serum potassium & $4.4 \pm 0.4$ & $4.3 \pm 0.4$ & $4.5 \pm 0.5$ & 0.070 \\
\hline Creatinine (mg/dL) & $1.2 \pm 0.9$ & $1.1 \pm 0.2$ & $1.2 \pm 0.4$ & 0.640 \\
\hline GFR (Mayo) & $86.2 \pm 19.7$ & $86.8 \pm 17.3$ & $84.7 \pm 22.4$ & 0.496 \\
\hline Diuretics & $33(26.61 \%)$ & 35 (32.71\%) & $50(46.3 \%)$ & 0.006 \\
\hline Antihypertensive drugs & $93(75 \%)$ & 87 (81.31\%) & 96 (88.89\%) & 0.025 \\
\hline Lipid-lowering drugs & $58(46.77 \%)$ & 49 (45.79\%) & $62(57.41 \%)$ & 0.162 \\
\hline \multicolumn{5}{|l|}{ Plasma sphingolipids } \\
\hline C16SO ( $\mu \mathrm{mol} / \mathrm{L})$ & $15.26 \pm 6.46$ & $14.67 \pm 4.38$ & $14.5 \pm 5.03$ & 0.695 \\
\hline C16SA ( $\mu \mathrm{mol} / \mathrm{L})$ & $0.44 \pm 0.26$ & $0.48 \pm 0.21$ & $0.49 \pm 0.23$ & 0.096 \\
\hline C17SO ( $\mu \mathrm{mol} / \mathrm{L})$ & $8.11 \pm 3$ & $7.74 \pm 2.43$ & $7.31 \pm 2.38$ & 0.165 \\
\hline C18PhytoSO ( $\mu \mathrm{mol} / \mathrm{L})$ & $0.12 \pm 0.05$ & $0.11 \pm 0.04$ & $0.11 \pm 0.04$ & 0.792 \\
\hline C18SAdiene ( $\mu \mathrm{mol} / \mathrm{L})$ & $28.64 \pm 8.57$ & $27.21 \pm 6.86$ & $26.01 \pm 7.68$ & 0.033 \\
\hline C18SO ( $\mu \mathrm{mol} / \mathrm{L})$ & $94.56 \pm 22.14$ & $92.67 \pm 19.29$ & $90.3 \pm 19.85$ & 0.250 \\
\hline C18SA ( $\mu \mathrm{mol} / \mathrm{L})$ & $3.16 \pm 1.44$ & $3.38 \pm 1.15$ & $3.7 \pm 1.69$ & 0.027 \\
\hline C19SO ( $\mu \mathrm{mol} / \mathrm{L})$ & $2.88 \pm 1.33$ & $2.82 \pm 1.15$ & $2.62 \pm 1.08$ & 0.262 \\
\hline C20SO ( $\mu \mathrm{mol} / \mathrm{L})$ & $0.17 \pm 0.06$ & $0.18 \pm 0.05$ & $0.18 \pm 0.05$ & 0.028 \\
\hline C20SA ( $\mu \mathrm{mol} / \mathrm{L})$ & $0.02 \pm 0.01$ & $0.03 \pm 0.01$ & $0.03 \pm 0.02^{\star}$ & 1.33E-05 \\
\hline 1-deoxySO ( $\mu \mathrm{mol} / \mathrm{L})$ & $0.14 \pm 0.1$ & $0.17 \pm 0.09$ & $0.22 \pm 0.14^{\star}$ & 2.22E-06 \\
\hline 1-deoxySA $(\mu \mathrm{mol} / \mathrm{L})$ & $0.07 \pm 0.05$ & $0.08 \pm 0.03$ & $0.09 \pm 0.05$ & 0.001 \\
\hline
\end{tabular}

Values are shown as mean \pm SD for the continuous variables and numbers and percentage of total for the categorical variables. $p$ Values were calculated using the ANOVA followed by the Bonferroni correction on the log transformed continuous variables. For the categorical variables, the $p$ value was calculated using the $\chi^{2}$ test. Variables in bold font have significant differences after the Bonferroni correction $\left(p=4.1 \times 10^{-4}\right)$. The three groups were compared with each other.

${ }^{*}$ Represent a significant difference from NFG.

$\S$ Represents a significant difference from IFG.

ANOVA, analysis of variance; ATP, Adult Treatment Panel; BMI, body mass index; CRP, C reaction protein; GFR (Mayo) Glomerular filtration rate (Mayo equation); $\mathrm{Hb}$, hemoglobin; $\mathrm{HbA1c}$, glycated $\mathrm{Hb}$; $\mathrm{HDL}$, high-density lipoprotein; HOMA-IR, Homeostatic model assessment-insulin resistance; IFG, impaired fasting glucose; LDL, low-density lipoprotein; MetS, metabolic syndrome; NFG, normal fasting glucose; SA, sphinganine; SO, sphingosine; T2DM, type 2 diabetes mellitus. 
sphingoid bases in plasma but refer to the sphingoid base composition of all plasma sphingolipids (independent whether free or $N$-acylated).

\section{Statistical analysis}

Continuous variables were log-transformed and the means were compared using the two-sided t test or analysis of variance followed by the Bonferroni correction. Categorical variables were compared using the $\chi^{2}$ test. Prospective analysis for the development of T2DM was performed using binary logistic regression. Mean comparisons were done between those individuals who developed T2DM and those who did not. A two-sided $\mathrm{t}$ test was performed on the log-transformed variables. Univariate binary logistic regression models were calculated to evaluate the predictive role of each of the measured variables. Multivariate logistic regression models were then performed to adjust for the traditional predictors. Since the number of cases in the incident T2DM group is 32, we limited the number of independent variables to two to avoid overfitting. Log-transformed and normalized variables in SD units were used for the logistic regression models. Statistical analyses were performed in SPSS V.16.0 (IBM, Zurich, Switzerland).

\section{RESULTS}

In a cross-sectional design, we first compared the sphingoid base plasma profiles from patients with and without MetS (table 1) as well as from participants with NFG, IFG, and T2DM (table 2).

At baseline, plasma concentrations of 1-deoxySLs and $\mathrm{C}_{20} \mathrm{SA}$-based sphingolipids were significantly higher in patients with MetS (table $1 ; \mathrm{p}=5.56 \times 10^{-6}$ for 1-deoxySO, $\mathrm{p}=3.26 \times 10^{-5}$ for 1-deoxySA, and $\mathrm{p}=2.81 \times 10^{-4}$ for $\mathrm{C}_{20} \mathrm{SA}$ ). Other sphingoid bases such as $\mathrm{C}_{16} \mathrm{SO}, \mathrm{C}_{17} \mathrm{SO}, \mathrm{C}_{18}$ SAdiene, $\mathrm{C}_{18} \mathrm{SO}$, and $\mathrm{C} 19 \mathrm{SO}$ were lower but did not reach statistical significance after correction for multiple comparisons.

Both 1-deoxySO and 1-deoxySA were elevated in patients with T2DM (table 2) and in patients with IFG but only 1-deoxySO remained significantly elevated after the Bonferroni correction for multiple comparisons $\left(\mathrm{p}<4.1 \times 10^{-4}\right)$. It should be noted that Bonferroni correction is a very rather conservative correction method that increases the likelihood of false negatives. Therefore, the lack of significance for 1-deoxySA in patients with T2DM after correction cannot be necessarily interpreted as no difference in 1-deoxySA levels. It is rather likely that this is a false-negative finding as two independent cohorts showed a significant increase in 1-deoxySA and 1-deoxySO in patients with T2DM. ${ }^{18} 23$ Interestingly, C20SA was also found to be significantly elevated in patient with T2DM. Other sphingoid bases were not significantly different.

Correlation analysis (table 3) revealed a strong positive correlation between 1-deoxySLs, TGs, glucose, HbA1c, insulin, and homeostatic model assessment-insulin

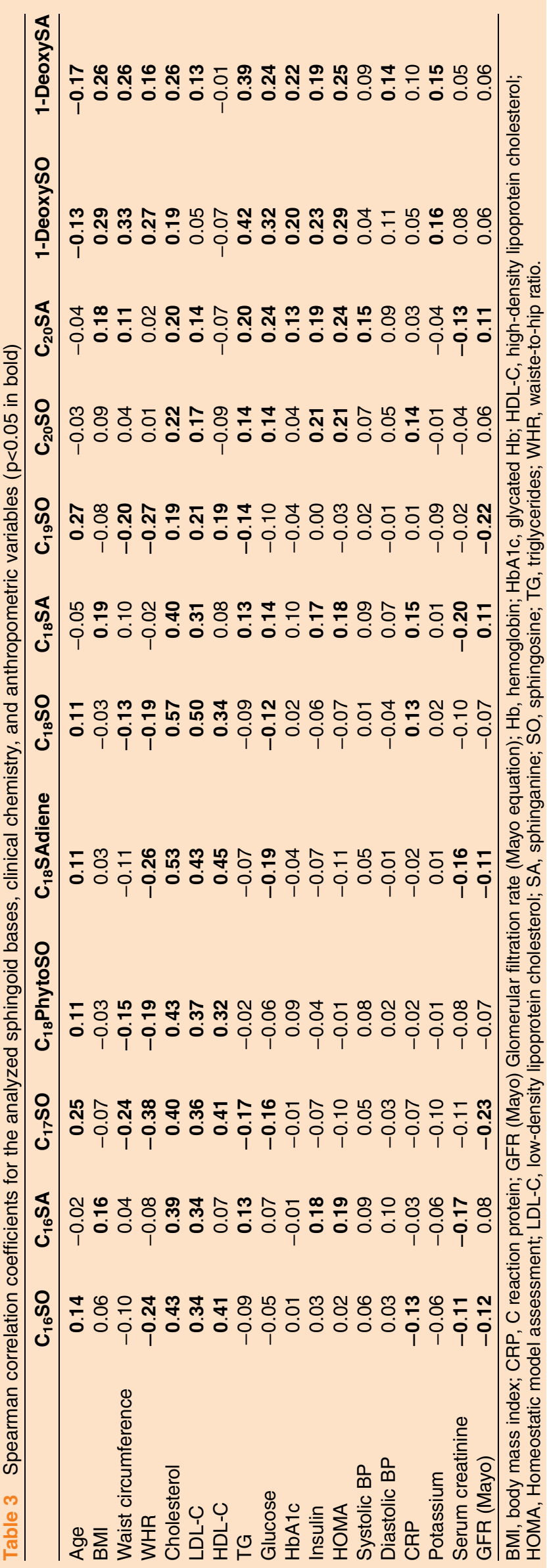


resistance while the serine-derived sphingolipids correlated with low-density lipoprotein cholesterol and total cholesterol.

The potential of plasma sphingoid bases as biomarkers to predict the risk to develop T2DM was assessed by comparing baseline levels between individuals who developed T2DM during the follow-up period of the study (incident T2DM, n=32) and those who did not (no incident T2DM, $n=70$ ). Baseline 1-deoxySLs were significantly higher in the incident T2DM group (table 4) as were HbA1c and TGs, $(\mathrm{p}=0.004$ for 1 -deoxySO, $\mathrm{p}=0.011$ for 1-deoxySA, $\mathrm{p}=0.006$ for HbA1c, and $\mathrm{p}=0.024$ for TGs).
Univariate binary logistic regression (table 5) revealed that 1-deoxySLs, along with typical risk factors such as HbA1c, TGs, hypertension, and the presence of an MetS, were significant predictors for the development of T2DM. Surprisingly also, serum potassium was a predictor for incident T2DM in the univariate analysis, which is in accordance with a recent report from the Atherosclerosis Risk in Communities (ARIC) study. ${ }^{24}$

The predictive potential of the 1-deoxySLs was further evaluated in a bivariate binary logistic regression model by using each of the significant variables from the univariate models as covariates (table 5) as well as other

Table 4 Baseline values of clinical variables and sphingolipid levels in the incident T2DM group and the group which did not develop T2DM until the end of the study period (8 years)

\begin{tabular}{|c|c|c|c|}
\hline & No iT2DM $(n=70)$ & iT2DM (n=32) & p Value \\
\hline Age (years) & $61.3 \pm 9.1$ & $64.8 \pm 10.7$ & 0.130 \\
\hline Sex (female) & $26(37.14 \%)$ & $11(34.38 \%)$ & 0.787 \\
\hline Hypertension (WHO) & $28(40 \%)$ & $19(59.38 \%)$ & 0.069 \\
\hline History of smoking & $37(52.86 \%)$ & $14(43.75 \%)$ & 0.393 \\
\hline Coronary artery stenosis $>50 \%$ & $38(54.29 \%)$ & $23(71.88 \%)$ & 0.093 \\
\hline MetS ATP III Definition & $15(21.43 \%)$ & $14(43.75 \%)$ & 0.020 \\
\hline BMI & $26.4 \pm 3.3$ & $27 \pm 5.3$ & 0.722 \\
\hline Waist circumference (cm) & $92.5 \pm 10.5$ & $96.6 \pm 13.8$ & 0.162 \\
\hline Waist-to-hip ratio & $0.9 \pm 0.1$ & $1 \pm 0.1$ & 0.150 \\
\hline Cholesterol (mmol/L) & $5.6 \pm 1$ & $5.8 \pm 1.3$ & 0.670 \\
\hline LDL (mmol/L) & $3.5 \pm 0.8$ & $3.4 \pm 0.9$ & 0.659 \\
\hline $\mathrm{HDL}(\mathrm{mmol} / \mathrm{L})$ & $1.3 \pm 0.4$ & $1.3 \pm 0.4$ & 0.900 \\
\hline Triglycerides (mmol/L) & $1.6 \pm 0.9$ & $2.2 \pm 1.6$ & 0.024 \\
\hline Glucose (mmol/L) & $5.8 \pm 1.1$ & $5.8 \pm 0.9$ & 0.793 \\
\hline HbA1c (\%) & $5.7 \pm 0.4$ & $6 \pm 0.5$ & 0.006 \\
\hline Insulin ( $\mu \mathrm{U} / \mathrm{mL})$ & $9 \pm 4.6$ & $16 \pm 26.6$ & 0.249 \\
\hline HOMA-IR & $2.3 \pm 1.2$ & $2.9 \pm 2.2$ & 0.576 \\
\hline Systolic BP & $131.6 \pm 19.1$ & $140.5 \pm 21.1$ & 0.041 \\
\hline Diastolic BP & $76.5 \pm 11$ & $79.8 \pm 14.1$ & 0.295 \\
\hline CRP & $0.7 \pm 1$ & $0.8 \pm 1.5$ & 0.773 \\
\hline Serum potassium & $4.3 \pm 0.4$ & $4.5 \pm 0.3$ & 0.027 \\
\hline Creatinine (mg/dL) & $1.1 \pm 0.1$ & $1.2 \pm 1$ & 0.194 \\
\hline GFR (Mayo) & $89.5 \pm 15.3$ & $85 \pm 23$ & 0.111 \\
\hline Diuretics & $20(28.57 \%)$ & $12(37.5 \%)$ & 0.367 \\
\hline Antihypertensive drugs & $57(81.43 \%)$ & $31(96.88 \%)$ & 0.035 \\
\hline Lipid-lowering drugs & $37(52.86 \%)$ & $16(50 \%)$ & 0.789 \\
\hline C16SO ( $\mu \mathrm{mol} / \mathrm{L})$ & $15.27 \pm 5.34$ & $16.29 \pm 8.99$ & 0.937 \\
\hline C16SA ( $\mu \mathrm{mol} / \mathrm{L})$ & $0.46 \pm 0.19$ & $0.52 \pm 0.42$ & 0.518 \\
\hline C17SO ( $\mu \mathrm{mol} / \mathrm{L})$ & $7.96 \pm 2.78$ & $8.66 \pm 3.88$ & 0.874 \\
\hline C18PhytoSO ( $\mu \mathrm{mol} / \mathrm{L})$ & $0.11 \pm 0.04$ & $0.13 \pm 0.09$ & 0.284 \\
\hline C18SAdiene ( $\mu \mathrm{mol} / \mathrm{L})$ & $28.37 \pm 7.55$ & $30.76 \pm 12.14$ & 0.566 \\
\hline C18SO ( $\mu \mathrm{mol} / \mathrm{L})$ & $93.08 \pm 19.41$ & $101.83 \pm 32.38$ & 0.188 \\
\hline C18SA ( $\mu \mathrm{mol} / \mathrm{L})$ & $3.28 \pm 1.12$ & $3.66 \pm 2.17$ & 0.518 \\
\hline C19SO ( $\mu \mathrm{mol} / \mathrm{L})$ & $2.8 \pm 1.14$ & $3.07 \pm 1.48$ & 0.470 \\
\hline C20SO ( $\mu \mathrm{mol} / \mathrm{L})$ & $0.17 \pm 0.05$ & $0.19 \pm 0.08$ & 0.187 \\
\hline C20SA ( $\mu \mathrm{mol} / \mathrm{L})$ & $0.02 \pm 0.01$ & $0.03 \pm 0.02$ & 0.613 \\
\hline 1-deoxySO ( $\mu \mathrm{mol} / \mathrm{L})$ & $0.14 \pm 0.06$ & $0.2 \pm 0.17$ & 0.004 \\
\hline 1-deoxySA ( $\mu \mathrm{mol} / \mathrm{L})$ & $0.07 \pm 0.03$ & $0.09 \pm 0.08$ & 0.011 \\
\hline
\end{tabular}

$p$ Values are calculated using the $t$ test on the log transformed variables (variables in bold font are $p<0.05$ ).

ATP, Adult Treatment Panel; BMI, body mass index; CRP, C reaction protein; GFR (Mayo) Glomerular filtration rate (Mayo equation); Hb, hemoglobin; HbA1c, glycated Hb; HDL, high-density lipoprotein; HOMA-IR, Homeostatic model assessment-insulin resistance; iT2DM, incident type 2 diabetes mellitus; LDL, low-density lipoprotein; MetS, metabolic syndrome; SA, sphinganine; SO, sphingosine. 
Table 5 Binary logistic regression models results for incident T2DM showing the ORs for the univariate and multivariate models

\begin{tabular}{|c|c|c|c|}
\hline & & OR $(95 \% \mathrm{Cl})$ & p Value \\
\hline \multicolumn{4}{|l|}{ Univariate binary logistic regression models } \\
\hline & 1-deoxyso & $2.09(1.22-3.58)$ & 0.007 \\
\hline & 1-deoxySA & $1.83(1.12-2.99)$ & 0.016 \\
\hline & TG & $1.69(1.05-2.7)$ & 0.030 \\
\hline & HbA1c & $4.11(1.42-11.85)$ & 0.009 \\
\hline & Systolic BP & $1.64(1.01-2.65)$ & 0.044 \\
\hline & Potassium & $1.78(1.05-3.03)$ & 0.03 \\
\hline & MetS & $2.85(1.16-7.03)$ & 0.023 \\
\hline \multicolumn{4}{|l|}{ Multivariate binary logistic regression models } \\
\hline \multirow[t]{2}{*}{ Model 1} & 1-deoxyso & $2.32(1.31-4.12)$ & 0.004 \\
\hline & Age & $1.63(0.99-2.69)$ & 0.054 \\
\hline \multirow[t]{2}{*}{ Model 2} & 1-deoxyso & $2.13(1.23-3.7)$ & 0.007 \\
\hline & Sex & $1.17(0.46-2.96)$ & 0.746 \\
\hline \multirow[t]{2}{*}{ Model 3} & 1-deoxyso & $2.05(1.2-3.5)$ & 0.008 \\
\hline & $\mathrm{BMI}$ & $1.09(0.68-1.75)$ & 0.731 \\
\hline \multirow[t]{2}{*}{ Model 4} & 1-deoxySO & $1.97(1.13-3.43)$ & 0.017 \\
\hline & MetS & $2.37(0.93-6.06)$ & 0.071 \\
\hline \multirow[t]{2}{*}{ Model 5} & 1-deoxySO & $2.1(1.22-3.59)$ & 0.007 \\
\hline & Lipid-lowering drugs & $0.85(0.36-2.04)$ & 0.720 \\
\hline \multirow[t]{2}{*}{ Model 6} & 1-deoxySO & $1.76(0.94-3.27)$ & 0.076 \\
\hline & TG & $1.31(0.75-2.27)$ & 0.344 \\
\hline \multirow[t]{2}{*}{ Model 7 (stepwise logistic regression) } & 1-deoxySO & 2.03 (1.19-3.49) & 0.010 \\
\hline & Zlog_TG & & 0.342 \\
\hline \multirow[t]{2}{*}{ Model 8} & 1-deoxyso & $2.1(1.19-3.71)$ & 0.010 \\
\hline & HbA1c & $4.11(1.37-12.34)$ & 0.012 \\
\hline \multirow[t]{2}{*}{ Model 9} & 1-deoxyso & $2.13(1.22-3.72)$ & 0.008 \\
\hline & Systolic BP & $1.73(1.04-2.86)$ & 0.033 \\
\hline \multirow[t]{2}{*}{ Model 10} & 1-deoxyso & $1.88(1.03-3.42)$ & 0.039 \\
\hline & Potassium & $1.62(0.94-2.78)$ & 0.083 \\
\hline \multirow[t]{2}{*}{ Model 1} & 1-deoxySA & $2.0(1.19-3.36)$ & 0.009 \\
\hline & Age & $1.6(0.99-2.61)$ & 0.057 \\
\hline \multirow[t]{2}{*}{ Model 2} & 1-deoxySA & $1.83(1.12-3)$ & 0.017 \\
\hline & Sex & 0.93 (0.37-2.29) & 0.869 \\
\hline \multirow[t]{2}{*}{ Model 3} & 1-deoxySA & 1.82 (1.12-2.97) & 0.016 \\
\hline & $\mathrm{BMI}$ & $1.13(0.71-1.8)$ & 0.607 \\
\hline \multirow[t]{2}{*}{ Model 4} & 1-deoxySA & 1.68 (1.01-2.79) & 0.048 \\
\hline & MetS & $2.26(0.88-5.79)$ & 0.088 \\
\hline \multirow[t]{2}{*}{ Model 5} & 1-deoxySA & $1.83(1.12-3)$ & 0.016 \\
\hline & Lipid-lowering drugs & $0.88(0.37-2.09)$ & 0.770 \\
\hline \multirow[t]{2}{*}{ Model 6} & 1-deoxySA & $1.56(0.9-2.71)$ & 0.112 \\
\hline & TG & $1.38(0.81-2.36)$ & 0.234 \\
\hline \multirow[t]{2}{*}{ Model 7 (stepwise logistic regression) } & 1-deoxySA & $1.81(1.1-2.96)$ & 0.019 \\
\hline & $\mathrm{TG}$ & - & 0.230 \\
\hline \multirow[t]{2}{*}{ Model 8} & 1-deoxySA & $1.76(1.06-2.92)$ & 0.030 \\
\hline & HbA1c & 3.78 (1.29-11.13) & 0.016 \\
\hline \multirow[t]{2}{*}{ Model 9} & 1-deoxySA & 1.76 (1.07-2.89) & 0.025 \\
\hline & Systolic BP & 1.57 (0.96-2.56) & 0.071 \\
\hline \multirow[t]{2}{*}{ Model 10} & 1-deoxySA & $1.62(0.94-2.77)$ & 0.082 \\
\hline & Potassium & $1.69(0.99-2.9)$ & 0.055 \\
\hline
\end{tabular}

Variables are log transformed and standardized in SD units.

ORs are reported per increase of 1 SD unit. Variables in bold font are significant $(p<0.05)$.

$\mathrm{BMI}$, body mass index; BP, blood pressure; HbA1c, glycated Hb; MetS, metabolic syndrome; SA, sphinganine; SO, sphingosine; T2DM, type 2 diabetes mellitus; TG, triglycerides.

risk factors (age, sex, BMI) and the use of lipid-lowering drugs. Baseline 1-deoxySO remained significant predictors for the development of T2DM even after adjustment for age, sex, BMI, HbA1c, MetS, systolic blood pressure, serum potassium, or the use of lipid-lowering drugs (table 5). Interestingly, adjusting for TGs made both TGs and 1-deoxySO non-significant predictors while the regression model was still significant, possibly due to the 
high colinearity between TGs and 1-deoxySO. However, using stepwise logistic regression, plasma 1-deoxySO remained significantly included in the regression model while TGs became non-significant (table 5). 1-DeoxySA showed a similar independent predictive role with significant OR after adjusting for the same risk factors, apart from serum potassium which again had a high colinearity with 1-deoxySA.

\section{CONCLUSIONS}

In the current study, we showed that plasma 1-deoxySLs are elevated in T2DM and are novel and independent predictors of T2DM. In two previous cross-sectional studies, we found that 1-deoxySLs are elevated in the plasma of patients with MetS ${ }^{18}$ and T2DM. ${ }^{19}$ These previous findings were confirmed in this study. In extension of our previous findings, we also showed that 1-deoxySLs are elevated in patients with IFG, suggesting that these lipids are already elevated in an early phase of T2DM. We also found that elevated 1-deoxySLs plasma levels are significantly and independently associated with an increased risk of developing T2DM after adjusting for several traditional risk factors and lipid-lowering drugs.

Pathologically elevated plasma 1-deoxySLs were originally found in the context of a rare inherited sensory neuropathy (Hereditary sensory and autonomic neuropathy type I, HSAN1) which is associated with several missense mutations in SPT. ${ }^{25-27}$ These mutations induce a shift in the substrate specificity of the enzyme that results in an increased 1-deoxySL formation. ${ }^{27}$ Further studies showed that 1-deoxySLs are neurotoxic and accumulate in the peripheral nerves but not in the brain or other organs of transgenic HSAN1 animals. ${ }^{27} 28$ However, it is not fully understood why 1-deoxySLs are also elevated in conditions of metabolic disorders such as MetS or T2DM. Cell culture studies showed that the increased availability of alanine alone is not sufficient to induce a significant 1-deoxySL formation. In contrast, cells which were either cultured at high density or which were treated with the CerS inhibitor fumonisin B1 (FB1) generate significant amounts of 1-deoxySLs. ${ }^{17}$ This suggests that a yet unknown regulatory mechanism is underlying the formation of these lipids in metabolic diseases. Elevated 1-deoxySL levels were also found in plasma of high fat and high fructose fed prediabetic and diabetic monkeys. $^{29}$ This corroborates our observation that 1deoxySLs are already elevated early in the course of T2DM development. Since 1-deoxySLs are cytotoxic, it is conceivable that they could play a role in the pathogenesis of T2DM such as $\beta$-cell failure and other T2DM-related sequelae, like retinopathy or diabetic neuropathy. Indeed, the addition of 1-deoxySA is toxic to $\beta$ cells in culture and results in cytoskeletal aberrations and cell death. ${ }^{30}$ These effects were at least partly mediated though JNK and p38 MAPK pathways. In the same work, we showed that 1-deoxySA compromises glucose-stimulated insulin secretion from primary $\beta$ cells in vitro. These findings further support the notion that 1-deoxySLs are not only early biomarkers in the course of T2DM development but might also be involved in the pathogenesis of T2DM. Given their reported neurotoxic activity in HSAN1, it is also feasible that 1-deoxySLs play a role in the pathogenesis of the diabetic neuropathy. Recently, we showed that lowering plasma 1-deoxySL with L-serine was associated with a significant improvement in the neuropathy in a diabetic rat model. ${ }^{31}$ This indicates that 1-deoxySLs act as both predictive biomarkers and potential therapeutic targets in T2DM.

We also found that plasma $\mathrm{C}_{20} \mathrm{SA}$ levels are increased in patients with IFG and T2DM. The origin and mechanisms by which plasma $\mathrm{C}_{20} \mathrm{SA}$ is formed are not fully clear yet. It has been shown that stearoyl coenzyme $\mathrm{A}$ is used by SPT as a substrate to form $\mathrm{C}_{20}$ sphingoid bases. ${ }^{32}$ The mechanism that regulates such a substrate shift is not clearly elucidated but several factors could play a role. The small SPT subunits $(\mathrm{ssSPTa} / \mathrm{b})^{8}$ which interact with SPT can modulate the affinity of SPT for various acyl coenzyme A substrates. Moreover, we have shown that the SPTLC3 subunit influences the affinity of SPT for various acyl coenzyme As. ${ }^{10} 33$ Whether these proteins play a role in the pathogenesis of T2DM or whether plasma $\mathrm{C}_{20} \mathrm{SA}$ levels are associated with other pathological processes related to T2DM is currently not clear.

The availability of 8-year follow-up data including biannual oral glucose tolerance tests is a substantial strength of this study. However, the total number of patients who developed incident T2DM during the follow-up period was limited and did not allow us to adjust for all possible confounders without the risk of over-fitting. At that point, we cannot fully exclude a possible influence of other confounders than $\mathrm{HbAlc}$ and MetS which were adjusted for. Furthermore, the investigated individuals were hospitalized with chest pain and underwent coronary angiography for the evaluation of established or suspected CAD. Our study cohort may therefore be at a higher risk to develop T2DM than the general population. Despite these limitations, the study showed that 1-deoxySO and 1-deoxySA levels are significant, independent, and predictive risk markers and comparable to other established risk factors like HbAlc and MetS.

However, larger and optimally interventional studies are needed to further confirm the clinical relevance of 1-deoxySLs as prognostic biomarkers and to explore their potential in the risk management of patients with MetS and T2DM.

Contributors AO performed the lipid extraction, mass spectrometric analysis and statistical analysis, and wrote the manuscript. AM and AV were involved in study design, sample collection, and patient characterization. CHS and HD were involved in study design, sample collection and patient characterization, and critically revised the manuscript. AvE and TH contributed to study design, data interpretation, and critically revised the manuscript. TH is the guarantor.

Funding This work was supported by grants from the Zurich Center of Integrated Human Physiology, University of Zurich (ZIHP); the 7th Framework Program of the European Commission ('RESOLVE', Project number 305707) and 'radiz'-Rare Disease Initiative Zurich, University of Zurich. 
Competing interests None.

Patient consent Obtained.

Ethics approval Ethics Committee of the University of Innsbruck.

Provenance and peer review Not commissioned; externally peer reviewed.

Data sharing statement No additional data are available.

Open Access This is an Open Access article distributed in accordance with the Creative Commons Attribution Non Commercial (CC BY-NC 4.0) license, which permits others to distribute, remix, adapt, build upon this work noncommercially, and license their derivative works on different terms, provided the original work is properly cited and the use is non-commercial. See: http:// creativecommons.org/licenses/by-nc/4.0/

\section{REFERENCES}

1. Abdul-Ghani MA, DeFronzo RA. Plasma glucose concentration and prediction of future risk of type 2 diabetes. Diabetes Care 2009;32: S194-8

2. Gerstein HC, Santaguida $P$, Raina $P$, et al. Annual incidence and relative risk of diabetes in people with various categories of dysglycemia: a systematic overview and meta-analysis of prospective studies. Diabetes Res Clin Pract 2007:78:305-12.

3. Helfand M, Buckley DI, Freeman M, et al. Emerging risk factors for coronary heart disease: a summary of systematic reviews conducted for the US Preventive Services Task Force. Ann Intern Med 2009;151:496-507.

4. Gerszten RE, Wang TJ. The search for new cardiovascular biomarkers. Nature 2008;451:949-52.

5. Wang TJ, Larson MG, Vasan RS, et al. Metabolite profiles and the risk of developing diabetes. Nat Med 2011:17:448-53.

6. Wang-Sattler R, Yu ZH, Herder C, et al. Novel biomarkers for pre-diabetes identified by metabolomics. Mol Syst Biol 2012;8:615

7. Floegel A, Stefan N, Yu Z, et al. Identification of serum metabolites associated with risk of type 2 diabetes using a targeted metabolomic approach. Diabetes 2013;62:639-48.

8. Han G, Gupta SD, Gable K, et al. Identification of small subunits of mammalian serine palmitoyltransferase that confer distinct acyl-CoA substrate specificities. Proc Natl Acad Sci USA 2009;106:8186-91.

9. Hanada K. Serine palmitoyltransferase, a key enzyme of sphingolipid metabolism. Biochim Biophys Acta 2003;1632:16-30.

10. Hornemann T, Richard S, Rütti MF, et al. Cloning and initial characterization of a new subunit for mammalian serine-palmitoyltransferase. J Biol Chem 2006;281:37275-81.

11. Hla T, Dannenberg AJ. Sphingolipid signaling in metabolic disorders. Cell Metab 2012;16:420-34.

12. Stratford S, Hoehn KL, Liu F, et al. Regulation of insulin action by ceramide-dual mechanisms linking ceramide accumulation to the inhibition of Akt/protein kinase B. J Biol Chem 2004;279:36608-15.

13. Holland WL, Miller RA, Wang ZV, et al. Receptor-mediated activation of ceramidase activity initiates the pleiotropic actions of adiponectin. Nat Med 2011;17:55-63.

14. Haus JM, Kashyap SR, Kasumov T, et al. Plasma ceramides are elevated in obese subjects with type 2 diabetes and correlate with the severity of insulin resistance. Diabetes 2009;58:337-43.

15. Shui GH, Stebbins JW, Lam BD, et al. Comparative plasma lipidome between human and cynomolgus monkey: are plasma polar lipids good biomarkers for diabetic monkeys? PLOS ONE 2011;6:e19731.
16. Holland WL, Brozinick JT, Wang LP, et al. Inhibition of ceramide synthesis ameliorates glucocorticoid-, saturated-fat-, and obesity-induced insulin resistance. Cell Metab 2007;5:167-79.

17. Zitomer NC, Mitchell T, Voss KA, et al. Ceramide synthase inhibition by fumonisin B1 causes accumulation of 1-deoxysphinganine: a novel category of bioactive 1-deoxysphingoid bases and 1-deoxydihydroceramides biosynthesized by mammalian cell lines and animals. J Biol Chem 2009;284:4786-95.

18. Othman A, Rütti MF, Ernst $D$, et al. Plasma deoxysphingolipids: a novel class of biomarkers for the metabolic syndrome? Diabetologia 2012;55:421-31.

19. Bertea M, Rutti MF, Othman A, et al. Deoxysphingoid bases as plasma markers in diabetes mellitus. Lipids Health Dis 2010; 9:84.

20. Drexel $\mathrm{H}$, Aczel S, Marte $\mathrm{T}$, et al. Is atherosclerosis in diabetes and impaired fasting glucose driven by elevated LDL cholesterol or by decreased HDL cholesterol? Diabetes Care 2005;28:101-7.

21. Quehenberger $\mathrm{O}$, Armando $\mathrm{AM}$, Brown $\mathrm{AH}$, et al. Lipidomics reveals a remarkable diversity of lipids in human plasma. $J$ Lipid Res 2010;51:3299-305

22. Gorden DL, Myers DS, Ivanova PT, et al. Biomarkers of NAFLD progression: a lipidomics approach to an epidemic. $J$ Lipid Res 2015:56:722-36.

23. Wei N, Pan J, Pop-Busui R, et al. Altered sphingoid base profiles in type 1 compared to type 2 diabetes. Lipids Health Dis 2014;13:161.

24. Chatteriee R, Yeh HC, Shafi T, et al. Serum and dietary potassium and risk of incident type 2 diabetes mellitus: the Atherosclerosis Risk in Communities (ARIC) study. Arch Intern Med 2010;170:1745-51.

25. Dawkins JL, Hulme DJ, Brahmbhatt SB, et al. Mutations in SPTLC1, encoding serine palmitoyltransferase, long chain base subunit-1, cause hereditary sensory neuropathy type I. Nat Genet 2001;27:309-12.

26. Rotthier A, Auer-Grumbach $\mathrm{M}$, Janssens $\mathrm{K}$, et al. Mutations in the SPTLC2 subunit of serine palmitoyltransferase cause hereditary sensory and autonomic neuropathy type I. Am J Hum Genet 2010;87:513-22.

27. Penno A, Reilly MM, Houlden $\mathrm{H}$, et al. Hereditary sensory neuropathy type 1 is caused by the accumulation of two neurotoxic sphingolipids. J Biol Chem 2010;285:11178-87.

28. Garofalo K, Penno A, Schmidt BP, et al. Oral L-serine supplementation reduces production of neurotoxic deoxysphingolipids in mice and humans with hereditary sensory autonomic neuropathy type 1. J Clin Invest 2011;121:4735-45.

29. Brozinick JT, Hawkins E, Hoang Bui $\mathrm{H}$, et al. Plasma sphingolipids are biomarkers of metabolic syndrome in non-human primates maintained on a Western-style diet. Int J Obes (Lond) 2013;37:1064-70.

30. Zuellig RA, Hornemann T, Othman A, et al. Deoxysphingolipids, a novel biomarker for type 2 diabetes, are cytotoxic for insulinproducing cells. Diabetes 2014;63:1326-39.

31. Othman A, Bianchi R, Alecu I, et al. Lowering plasma 1-deoxysphingolipids improves neuropathy in diabetic rats. Diabetes 2015;64:1035-45.

32. Chigorno V, Valsecchi M, Sonnino S. Biosynthesis of gangliosides containing $\mathrm{C} 18: 1$ and $\mathrm{C} 20: 1$ [3-14C]sphingosine after administrating [1-14C]palmitic acid and [1-14C]stearic acid to rat cerebellar granule cells in culture. Eur J Biochem 1994;221:1095-101.

33. Hornemann T, Penno A, Rütti MF, et al. The SPTLC3 subunit of serine palmitoyltransferase generates short chain sphingoid bases. J Biol Chem 2009;284:26322-30. 